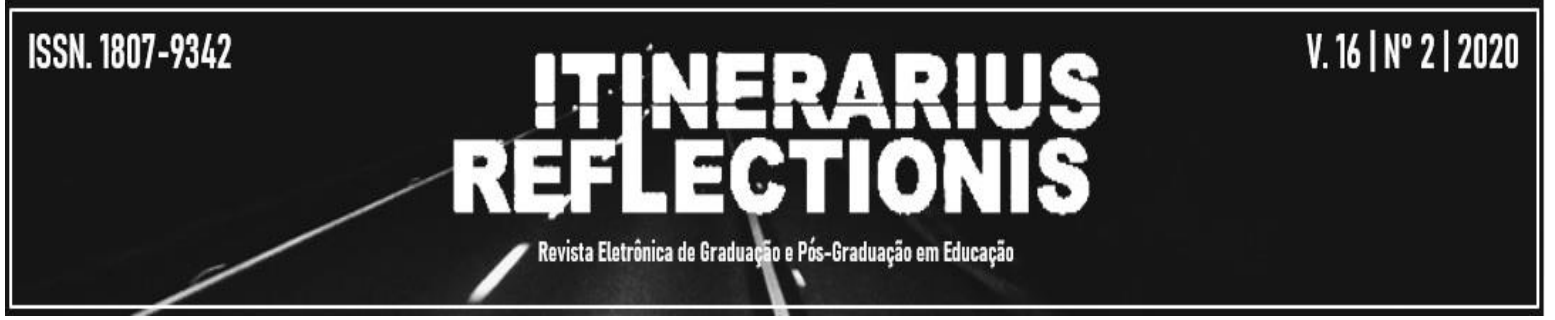

\title{
Percepção pública sobre a ciência em um evento sobre popularização da ciência em curitiba: paraná
}

\author{
Patrícia Shigunov ${ }^{1}$ \\ Bruna Falavinha ${ }^{2}$ \\ Thaisa Yumi Kataoka ${ }^{2}$ \\ Rodrigo Pedroso Madlener de Almeida ${ }^{2}$ \\ Wagner Nagib ${ }^{3}$ \\ Paula Renata Fontoura ${ }^{4}$
}

Resumo. Como atrair o interesse da população para a Ciência? Quais as possibilidades para o acesso ao conhecimento científico? Estes questionamentos originaram esse trabalho, que investigou a forma com que a população percebe a Ciência e quais são os canais de busca de informações que encontram. Os participantes foram convidados a responder um questionário sobre institutos de pesquisas, importância da ciência, hábito e fontes de informações. Apesar da unanimidade dos entrevistados sobre a importância da ciência, apenas 58\% têm o hábito de se informar sobre o tema e $80 \%$ destes utilizam a internet como fonte. Em relação a melhor forma de fazer divulgação científica: televisão, internet, aulas nas escolas e locais públicos foram as opções mais citadas. A revista científica, frequentemente utilizada pelos cientistas para comunicarem suas descobertas, foi a alternativa menos citada. Contudo, esse trabalho estabelece as fontes de informações sobre ciência mais utilizadas pela população.

Palavras-chave: Popularização da ciência. Divulgação científica. Fontes de informação.

\section{PUBLIC PERCEPTION ABOUT SCIENCE IN AN EVENT OF POPULARIZATION OF SCIENCE IN CURITIBA - PARANÁ}

\begin{abstract}
How to attract the interest of the population to Science? What are the possibilities for access to scientific knowledge? These questions originated this work, which investigated the way in which the population perceives Science and which are the channels of search of information that they find. The participants were invited to answer a questionnaire about research institutes, importance of science, habit and sources of information. Despite the unanimity of the interviewees about the importance of science, only 58\% have a habit of reporting on the subject and $80 \%$ of them use the internet as a source. Regarding the best way to make scientific dissemination: television, internet, classes in schools and public places were the most cited options. The scientific journal, often used by scientists to communicate their findings, was the less-cited alternative. However, this work establishes the most widely used sources of information about science.
\end{abstract}

Keywords: Popularization of Science. Dissemination. Sources of information.

\section{INTRODUÇÃ̃}

\footnotetext{
${ }^{1}$ Doutora em Biociências e Biotecnologia e Pesquisadora em Saúde Pública do Instituto Carlos Chagas FIOCRUZ - Paraná, patricia.shigunov@ fiocruz.br

${ }^{2}$ Mestrando(a) do Programa de Pós-graduação em Biociências e Biotecnologia do Instituto Carlos Chagas FIOCRUZ - Paraná. brunafalavinha@hotmail.com; thaisakataoka@hotmail.com; rod.pma@gmail.com

${ }^{3}$ Mestre em Formação Científica, Educacional e Tecnológica pela Universidade Tecnológica Federal do Paraná e Design Gráfico do Instituto Carlos Chagas - FIOCRUZ - Paraná. wagner.nagibe@ gmail.com

${ }^{4}$ Mestre em Formação Científica, Educacional e Tecnológica pela Universidade Tecnológica Federal do Paraná e Jornalista do Instituto Carlos Chagas - FIOCRUZ - Paraná. paula.fontoura@ fiocruz.br
} 


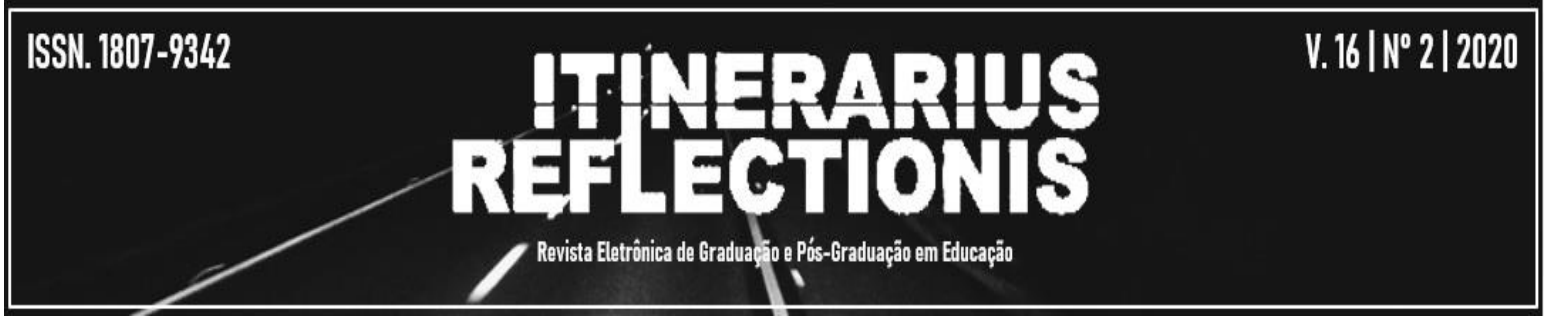

Em muitos debates sobre as relações entre ciência e sociedade, em particular quanto à aceitação das tecnologias ou à percepção de seus riscos, existe uma hipótese subjacente: a de que a ignorância gera medo, e o medo gera desconfiança ou hostilidade contra a ciência e a tecnologia (CASTELFRANCHI et al., 2013). Atitudes otimistas sobre ciência e tecnologia não dependem do nível escolar ou da informação declarada ou acessada pelas pessoas sobre o tema, tornando essa hipótese questionável (CASTELFRANCHI et al., 2013). No entanto, explicações pseudocientíficas e místicas ocupam cada vez mais os espaços dos meios de comunicação e há uma constante necessidade de recuperação dos valores da racionalidade. Carl Sagan (1996) já afirmou o pleno poder positivo e benéfico da ciência e da tecnologia, mas como fazer isso?

Há poucas informações sobre como a população aprende e busca informações sobre a ciência, exceto através do ensino regular. Será que a população tem interesse em novas descobertas da ciência e tecnologia? Onde a população busca esse conhecimento? Qual a melhor forma de atrair o interesse da população na ciência? Como envolver a população para a importância dos conhecimentos científicos? Com base nesses questionamentos, esse trabalho teve como objetivo principal saber mais sobre como a população vê e busca informações sobre a ciência, a fim de definir melhores estratégias para a popularização da ciência.

\section{METODOLOGIA}

O evento de popularização da ciência aconteceu na rua $\mathrm{XV}$, localizado no centro de Curitiba, Paraná (Figura 1). Uma equipe formada por 13 pessoas do Instituto Carlos Chagas (ICC/ FIOCRUZ PARANÁ) sendo 9 cientistas e 4 profissionais da assessoria de comunicação estiveram presentes no espaço falando sobre ciência com a população em geral. A tenda de quatro metros quadrados apresentou vários instrumentos de pesquisa, incluindo microscópio com lâminas de células-tronco, barbeiros, micropipetadores, gelo seco, tubos de plástico e frascos de cultivo celular. Dois dos integrantes se fantasiaram de mosquito da dengue e cientista maluco para atrair a atenção do público. Os visitantes do espaço foram convidados a participarem da pesquisa e informados sobre o objetivo do questionário. Antes de iniciar a pesquisa, os participantes assinaram o termo de consentimento livre e esclarecido ${ }^{5}$.

\footnotetext{
${ }^{5}$ Esse projeto teve parecer aprovado pelo Comitê de ética em pesquisa com humanos sob o número CAAE: 90640818.4.0000.5248.
} 


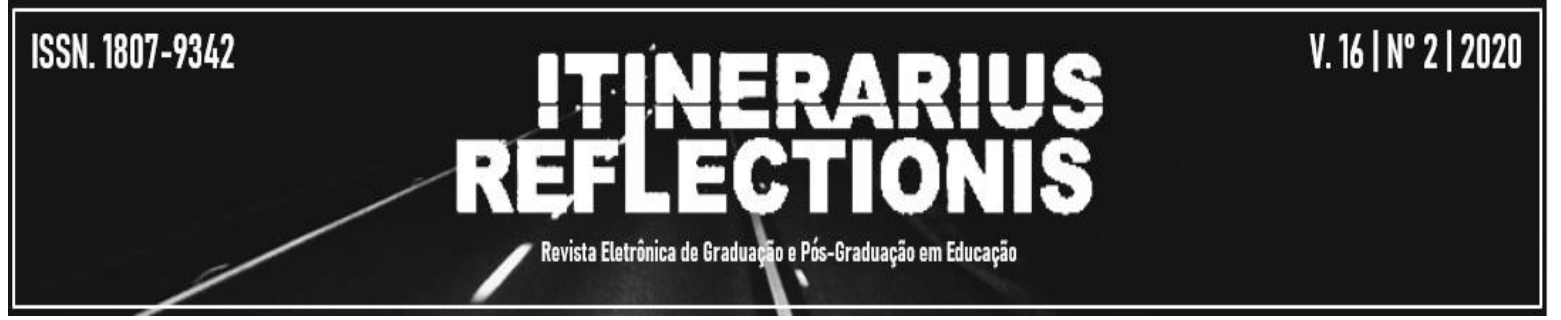

Um total de 43 pessoas aceitaram participar do projeto e responderam ao questionário semiestruturado (Anexo 1) contendo 12 questões, sendo 5 abertas e 7 com alternativas com opções "Outros". Os dados foram agrupados e cálculos de porcentagem foram aplicados e apresentados em forma de gráficos, seguindo uma análise quantitativa baseado em Knechtel (2014). Nessa pesquisa, alguns dados coletados são descritivos considerando as concepções e pontos de vista dos participantes denominado pesquisa qualitativa segundo Ludke e André (1986).

Figura 1. Imagens do evento de popularização da ciência denominado Fiocruz na Rua. Personagens fantasiados de mosquito da dengue e cientista maluco, chamaram a atenção da população. Fonte:

http://www.icc.fiocruz.br/fiocruz-na-rua/.

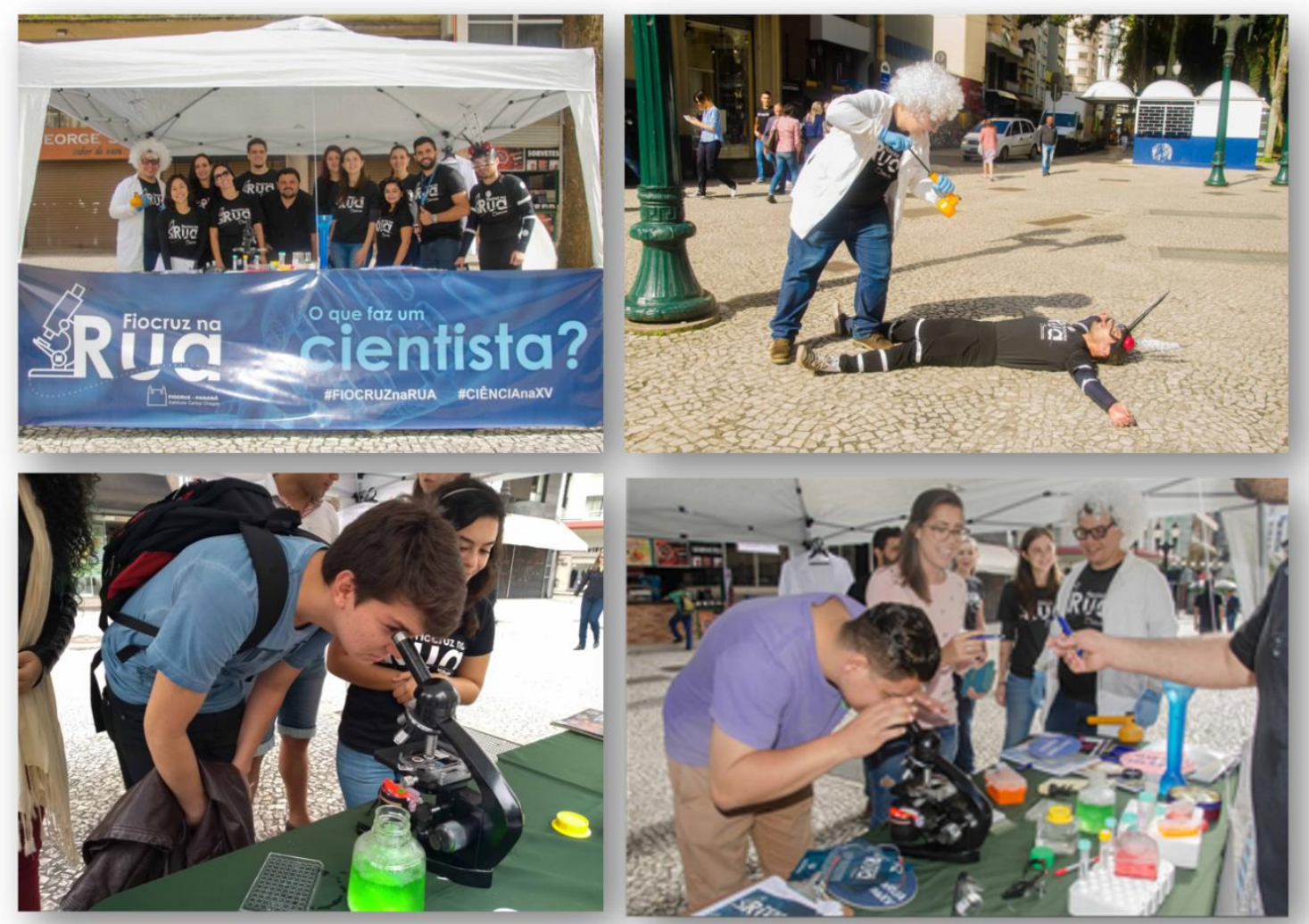

\section{RESULTADOS E DISCUSSÕES}

O evento de popularização da ciência realizado no Centro de Curitiba pela Fiocruz Paraná teve um público heterogêneo em relação a idade, com a participação de crianças a 


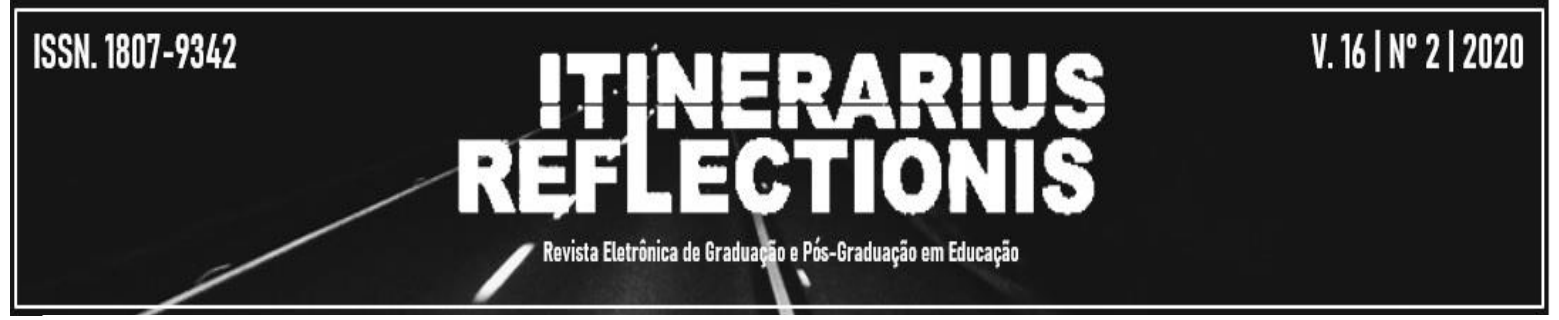

A

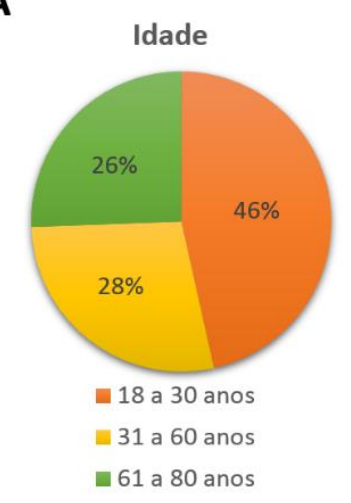

D

Você já sabia da existência de
institutos de pesquisa no Brasil?

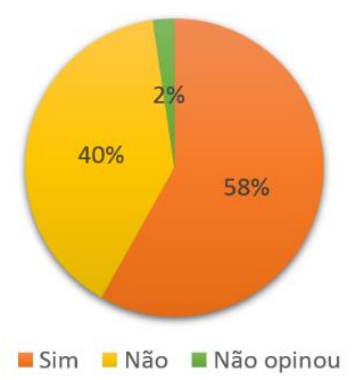

B

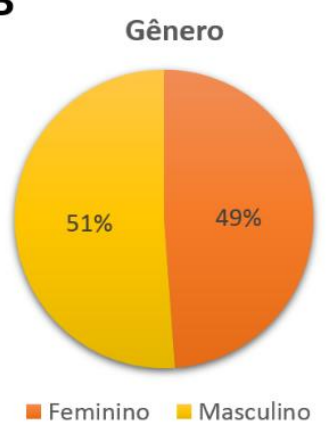

E

Você já sabia da existência de institutos de pesquisa no Brasil? Quais

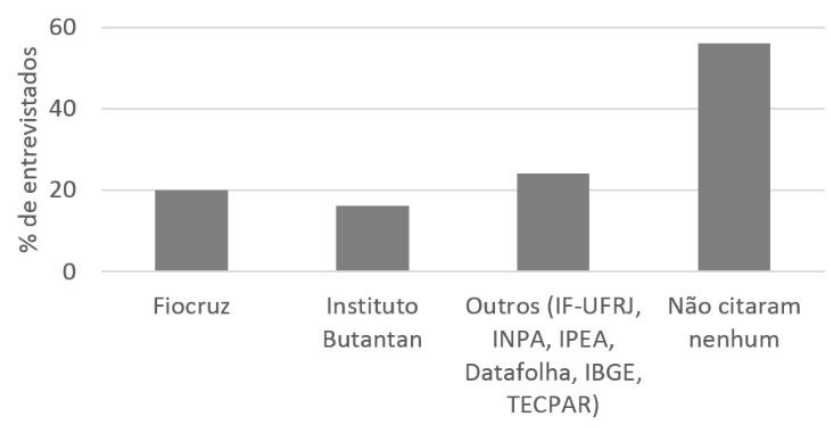

Os entrevistados foram unânimes quando questionados sobre a importância das pesquisas científicas (Figura 3A), embora o grau substancial dos entrevistados sobre a real compreensão das pesquisas científicas e sua importância não tenha sido avaliado. Alguns entrevistados podem afirmar a importância das pesquisas científicas para não decepcionar o entrevistador ou por não querer admitir a ausência de informação sobre a temática. Metade dos entrevistados citam os termos "doenças" e "cura" em suas respostas quando questionados o motivo da importância das pesquisas científicas (Figura 3B). É possível que a correlação das pesquisas científicas com questões da saúde, justifiquem o motivo da FIOCRUZ e Instituto Butantan serem as instituições mais citadas anteriormente. Ainda, cerca de $86 \%$ dos entrevistados determinaram a ciência como imprescindível para a vida das pessoas (Figura 3C). Essas informações corroboram com os resultados sobre percepção pública da ciência e tecnologia no Brasil de 2015, que segundo os entrevistados a área prioritária para investimentos é a dos medicamentos e tecnologias médicas (CGEE, 2015).

Figura 3. A importância das pesquisas científicas pelos entrevistados. (A) Gráfico representando a porcentagem de entrevistados que consideram as pesquisas científicas importantes. (B) Gráfico representando as palavras mais 


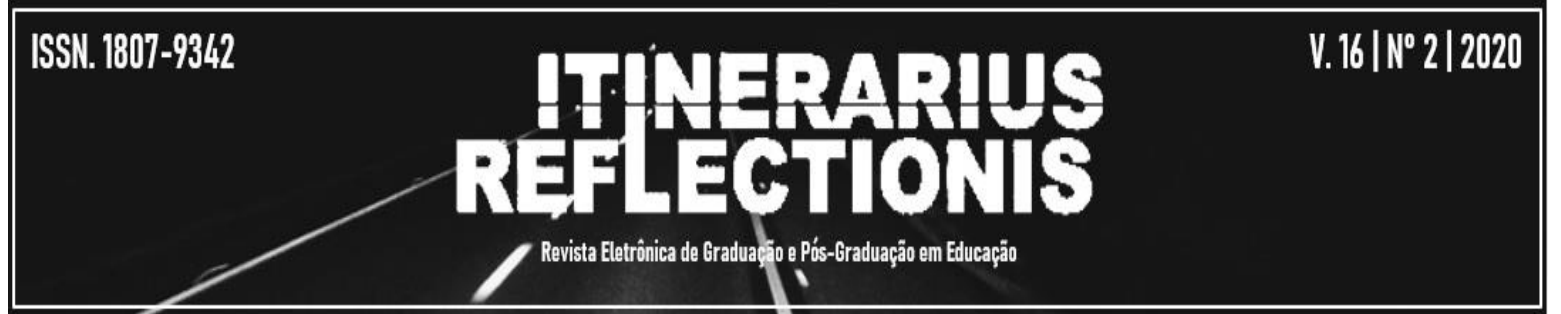

usadas para a definição do motivo da importância das pesquisas científicas. (C) Gráfico representando os graus de impacto da ciência na vida das pessoas, segundo os entrevistados. Grau 1= irrelevante; Grau 5 imprescindível. FONTE: Autor.

A

Você acha que as pesquisas
científicas são importantes?

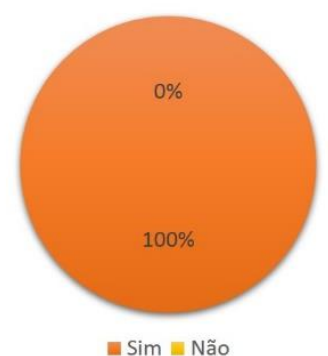

B

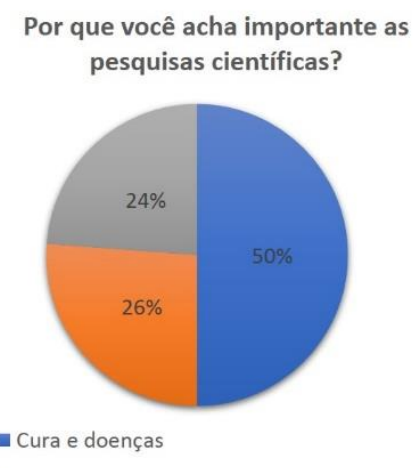

Educação, informação e conhecimento.

Descoberta, pesquisa, desenvolvimento tecnologia
C Qual o impacto da ciência na
vida das pessoas?

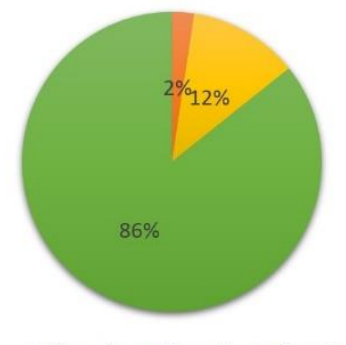

@ Grau $3 \cong$ Grau 4 @ Grau 5

Aproximadamente $68 \%$ dos entrevistados tem o costume de se informar sobre ciência, sendo a internet utilizada por mais de $80 \%$ dessas pessoas (Figura 4A-B). Segundo dados da pesquisa sobre percepção pública da ciência e tecnologia no Brasil (CGEE, 2015), a TV foi o meio mais usado para adquirir informações sobre ciência e tecnologia: $21 \%$ dos brasileiros fazem isso com muita frequência e $49 \%$ com pouca frequência. A falta de tempo e desconhecimento sobre onde procurar foram os motivos mais descritos pelas pessoas sem o hábito de se informar sobre ciência (Figura 4C). As revistas científicas são as fontes de informação menos utilizadas pelos entrevistados, empatando com os jornais. A revista científica é a forma de melhorar a divulgação científica menos significativa (Figura 4E). Contudo, as revistas científicas são, muitas vezes, as únicas fontes utilizadas pelos cientistas para divulgação de suas descobertas. O artigo científico é um documento indispensável e completo, pois apresenta todas as informações detalhadas de como os experimentos foram realizados e a descrição dos resultados gerados da pesquisa, porém ele é escrito, geralmente, em inglês e possui uma linguagem técnica de difícil compreensão. $\mathrm{O}$ artigo científico é destinado a leitores não leigos, que, via de regra, compreendem termos técnicos e/ou especializados sem maiores dificuldades (Furtado, 2016). Isso justifica o motivo do público em geral ter pouco interesse e acesso a esses documentos. Furtado (2016) propõe um ensino de ciência e tecnologia vinculado a questões sociais que procurem formar cidadãos críticos por meio de artigos de divulgação científica. Esse tipo de artigo é destinado a leitores leigos 


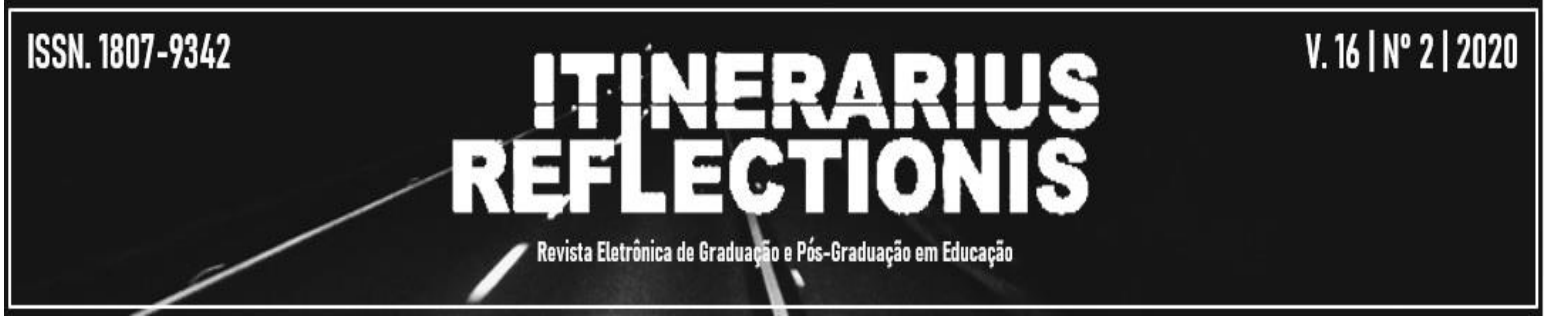

na área, mas que por meio de uma linguagem mais simples e objetiva, conseguirão se inteirar do assunto e compreendê-lo (Furtado, 2016).

Figura 4. Hábito da população em se informar sobre ciência. (A) Gráfico representando a porcentagem dos entrevistados que possuem o hábito de se informar. (B) Gráfico mostrando a porcentagem dos meios de comunicação mais utilizados entre os entrevistados que têm o hábito de se informar. (C) Gráfico mostrando a porcentagem dos motivos dos entrevistados de não terem o costume de se informar sobre ciência. (D) Gráfico representando a porcentagem de entrevistados que acham que a ciência deveria ser melhor divulgada. (E) Gráfico representando a porcentagem das melhores formas de fazer divulgação, segundo os entrevistados.

FONTE: Autor.

A

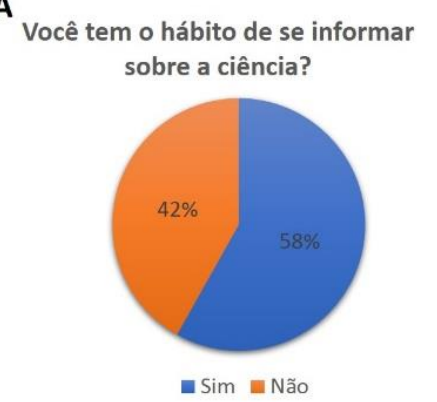

D

Você acha que a ciência deveria ser melhor divulgada no nosso país?

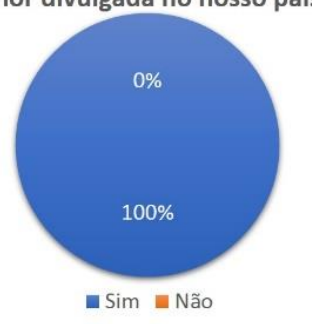

B

Qual o meio de comunicação que você mais utiliza para se informar?

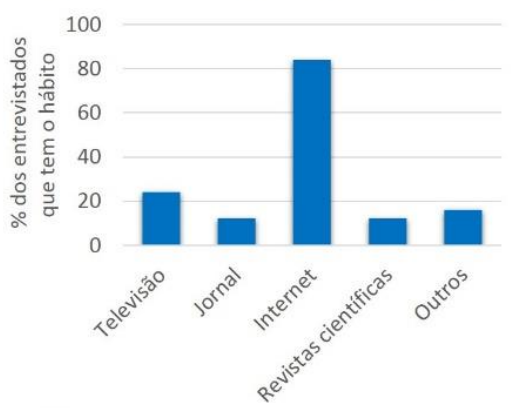

E
C

Quais os motivos para a falta desse hábito?
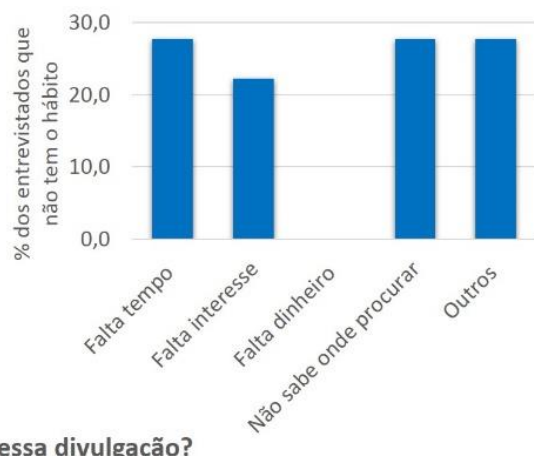

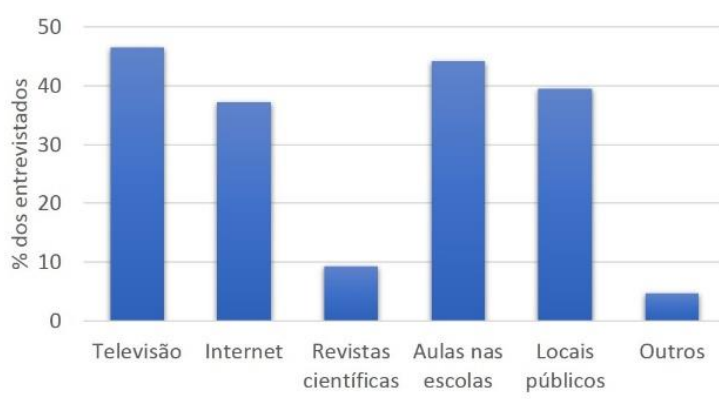

Segundo Carl Sagan (1996), a divulgação da ciência tem êxito se, de entrada, não faz mais que acender a faísca da curiosidade. Para isso basta oferecer um olhar aos descobrimentos da ciência sem explicar do todo como se obtiveram. Ao menos de vez em quando, as pessoas deveriam experimentar chegar a sua própria conclusão, ou seja, converter a assimilação obediente do novo conhecimento em um descobrimento pessoal (Sagan, 1996). Sagan descreve que quando a gente mesmo faz o descobrimento - embora seja a última pessoa da Terra em ver a luz - não o esquece nunca. Baseado nessa premissa, as fontes de informações de divulgação científica poderiam utilizar da estratégia de instigar e permitir a população a gerar essas descobertas induzidas com a finalizada de concretizar esses 


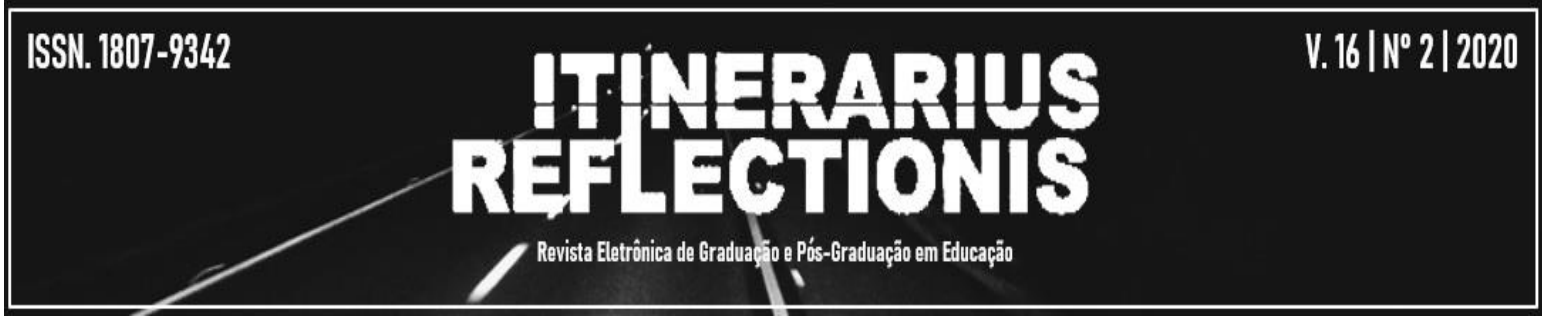

conhecimentos. Esse tipo de abordagem permite desenvolver a criticidade do indivíduo, já que podem indicar a consistência das afirmações; a clareza e a comprovação das pesquisas; a eventual existência de defesas de ordem pessoal e não consubstanciadas em critérios científicos; dentre outras inúmeras possibilidades (Furtado, 2016).

\section{CONSIDERAÇÕES FINAIS}

O conhecimento sobre a percepção da população sobre a ciência e como ela é buscada nos permite encontrar caminhos para aprimorar a popularização da ciência. A extensão nas universidades e instituições de pesquisa é um caminho para materializar a popularização da ciência apresentando resultados e respostas a sociedade. Nesse contexto, é fundamental as instituições ampliarem seus horizontes e fazerem a divulgação institucional e das pesquisas geradas em âmbito nacional para a população, bem como instigar a mídia televisiva a buscar notícias associadas a ciência, já que a população possui esse interesse e utiliza os programas de tv como fontes de informações científicas. Esse trabalho apresenta a internet como a maior fonte de informações sobre ciência, embora alguns entrevistados tenham citado dificuldades em onde buscar informações científicas na internet. Essa sinalização mostra a necessidade de desenvolver ferramentas de divulgação de informações científicas para o público em geral de diferentes formas: internet, TVs, locais públicos e escolas. Em relação às indispensáveis publicações em revistas científicas, é sabido que raramente será a fonte principal de conhecimento científico por parte da população. No entanto, os artigos de divulgação científica podem ocupar essa função informativa. Vale ressaltar que a escrita de artigos de divulgação científica é um novo nicho para profissionais com habilidades de realizarem a transposição do saber científico para o saber ensinado, profissionais esses conhecidos também como divulgadores científicos.

\section{REFERÊNCIAS}

BROWNELL, S.E., PRICE, J.V. \& STEINMAN L., Science Communication to the General Public: Why We Need to Teach Undergraduate and Graduate Students this Skill as Part of Their Formal Scientific Training, The Journal of Undergraduate Neuroscience Education (JUNE), Fall 2013, 12(1):E6-E10. 


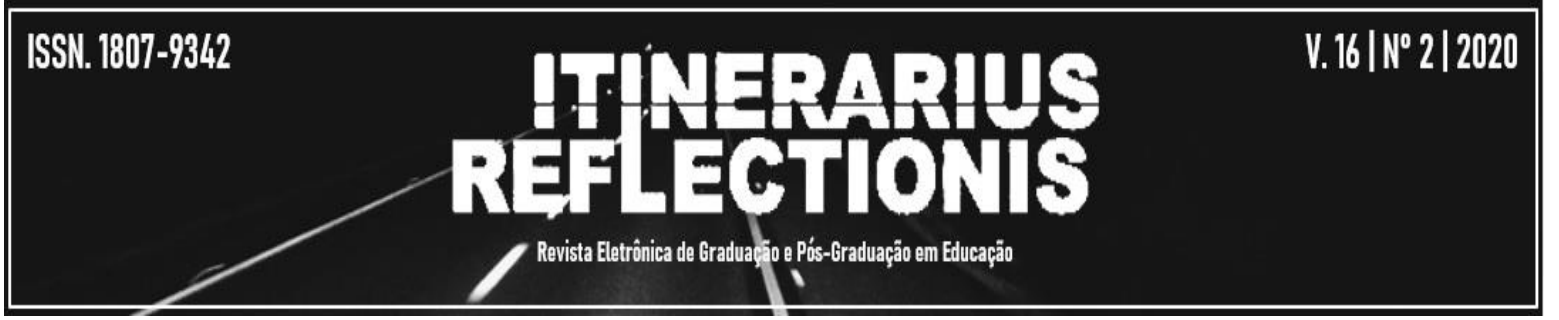

CGEE, 2015 - Percepção pública da ciência e tecnologia 2015 - Ciência e tecnologia no olhar dos brasileiros. Sumário executivo. Brasília: Centro de Gestão e Estudos Estratégicos, 2015. Disponível em: 〈https://www.cgee.org.br/documents/10182/734063/percepcao_web.pdf> Acesso em: 23 jan. 2019.

Furtado, V. F., GÊNERO ARTIGO DE DIVULGAÇÃO CIENTÍFICA: UMA POSSSIBILIDADE DE ABORDAGEM INTERDISCIPLINAR, Itinerarius Reflections, Volume 12, número:1, 2016

GREENWOOD M.R.C., RIORDAN D.G., Civic scientist/Civic Duty. Science Communication 23:28-40 (2001).

LESHNER A.I., Public engagement with science. Science 299:977 (2003).

LÜDKE, M; ANDRÉ, M. E. D. A. Abordagens qualitativas. São Paulo: EPU, 1986.

KNECHTEL, Maria do Rosário. Metodologia da pesquisa em educação: uma abordagem teórico-prática dialogada. Curitiba: Intersaberes, 2014.

SAGAN, Carl. O mundo assombrado por demônios: a ciência vista como uma vela na escuridão. São Paulo: Companhia das Letras. 1996.

Yurij Castelfranchi et al. As opiniões dos brasileiros sobre ciência e tecnologia: o 'paradoxo' da relação entre informação e atitudes, História, Ciências, Saúde - Manguinhos, Rio de Janeiro, v.20, n.2, abr.-jun. 2013, p.653-673 v.20, supl., nov. 2013, p.1163-1183 